\title{
Construction on Vocational Competency Model for Tourism Talents in Intelligent Tourism Era
}

\author{
Ji Luo \\ Benxi Television University, Benxi, 117000, China \\ 88461322@qq.com
}

Keywords: intelligent tourism; tourism talents; competency model; iceberg model

\begin{abstract}
The era of intelligent tourism has aroused changes in tourism consumption patterns, changes in tourism service methods, changes in tourism management methods, and changes in tourism marketing methods. The training of professional talents for tourism professionals in the era of intelligent tourism is not limited to skills and knowledge, but also comprehensive considerations in terms of ideological qualities and personal characteristics. Based on competency theory and iceberg model, this paper constructs the professional competency model for tourism talents in the era of intelligent tourism. The "above-iceberg part" consists of eight "visible" features. The "below-iceberg-part" consists of eight "invisible" features. The research results of this paper serve the education reform of colleges and universities, as well as the recruitment, selection, performance management and training for tourism enterprises.
\end{abstract}

\section{Introduction}

"Intelligent Tourism" is another new concept after "Intelligent World" and "Intelligent City". Since it was first proposed in 2010, it has received strong support from government departments, high recognition from the industry, and earnest discussion in the academic world. The National Tourism Administration has identified 2014 as the "Intelligent Travel Year", in order to promote the reform and innovation of the tourism promotion model, expand the use of new media and technologies, and guide the construction of intelligent tourism cities and tourism destinations. The Instruction on Promoting the Development of Intelligent Tourism promulgated by the National Tourism Administration in 2015 pointed out that the market-based development mechanism should be established, the mode of innovation encouraged in the guide mode, and the sustainable and healthy development of intelligent tourism should be promoted in an orderly manner so as to continuously improve the level of China's tourism informationization.

China is not only the big tourism destination but also the big tourism resource. Tourism has become an important leisure lifestyle for ordinary people. The "Instruction on Promoting the Development of Intelligent Tourism" of the National Tourism Administration pointed out that by 2020, China's intelligent tourism service capabilities will be significantly improved, and the wisdom management capability will continue to increase, and a number of companies with strong strengths in the intelligent tourism business will be fostered to form the system is the wisdom of the tourism value chain network. Intelligent tourism has become one of the important features and development trends in the current transformation and upgrading of the tourism industry. It is a profound change in the current tourism industry. It has changed the traditional tourism consumption mode, tourism management and management service model and administrative management model. The industry has transformed from the traditional service industry to the modern service industry. In this transformation and upgrading process, talents are the key. Under this background, it is of great theoretical and practical significance to carry out research on this topic. 


\section{Competency Theory}

Competency refers to the deep characteristics of individuals who can distinguish outstanding performers from ordinary people in a job. They can be motives, traits, self-images, attitudes or values, knowledge in a certain field, cognitive or behavioral skills, etc. Any individual characteristics that can be reliably measured or counted, and that can significantly distinguish excellent from general performance. At present, the definition of competency can be roughly divided into three categories: characteristic view, behavior view and comprehensive view. From the perspective of characteristics, competence is defined as potential and enduring individual characteristics; behavioral perception, competence is seen as the behavioral performance of an individual when performing an individual's job responsibilities, and competence is a dimension that guarantees the explicit behavior of the competent job; "behavioral view" and "characteristic view" of competency should complement each other, any one view is not comprehensive, and the connotation of competency should be defined in terms of "behavior view" and "character view". Therefore, the concept of "attribute set" was proposed, which combined tasks, output, and specific results with knowledge, skills, and motivation.

Taylor, the "Father of Scientific Management", believes that there is a difference between the situation in which excellent employees complete their work and the average employee completes their work. David McClelland, a professor of psychology at Harvard University in the United States, believes that high performers can achieve outstanding results mainly because they use certain specific knowledge and have some special talents and qualities. Through the research on outstanding performance personnel, they can find the reason for performance differences. As shown in Fig.1.

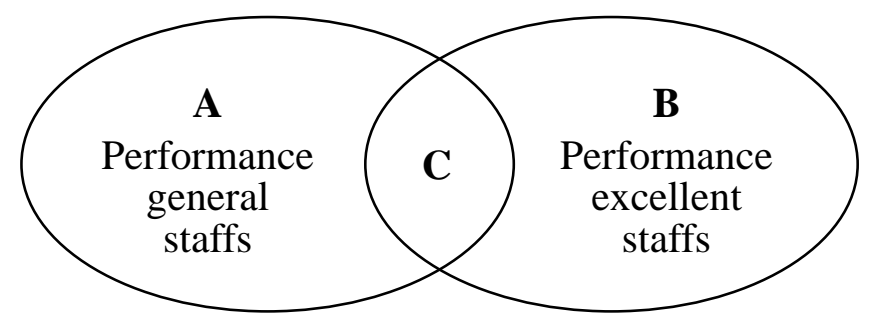

Fig. 1. Competency factors diagram

As shown in Fig.1, the part in the left circle represents the competency elements of the average person in the performance evaluation; the coincident part $C$, in the middle $A$ and $B$ represents the competency elements shared by the outstanding performance evaluation staff and the general staff; the right side B part, it represents the unique elements of outstanding performance in performance appraisal. Part B is exactly what the competencies require.

The competency theory can be analyzed from four aspects: first, the relationship between competency and performance is directly related to the individual's competency qualities directly affect job performance, there is a causal relationship between competency and performance, and competency can not only promote The high performance of the job can even predict the future job performance of employees. Second, the competency is related to the job position and the specific situation. The required competency for each position is determined by the position. Only in certain job positions or specific situations can the competency be formed. Only the individual knowledge associated with the work scenario can be used. Only qualities such as skills and social roles will be considered as competency. Therefore, the competency traits of different positions are different. Third, competencies can distinguish well-performing individuals from generally performing individuals. Fourth, the competency is measurable, that is, by observing and measuring the individual's performance in the actual work, summarizing the competence. 


\section{Competency Model}

The competency model is a competency structure that combines the outstanding performance of specific positions and is an important basis for a series of human resources management and development practices such as recruitment, selection, performance management, training and development. Competency representative models include iceberg models and onion models, which are constructed using iceberg models. The iceberg model is divided into visible parts of the "above iceberg" and invisible parts of the "ice below the iceberg," depending on how the individuals' abilities are expressed. Among them, "the part above the iceberg" includes basic knowledge and basic skills. It is an external performance, easy to understand and measure, and easier to change and develop through training. The "below the iceberg" includes social roles, self-recognition, traits and motivation. It is an intrinsically difficult part to measure. It is not easily changed through external influences, but it plays a key role in the behavior and performance of people. The iceberg model structure is shown in Fig.2.

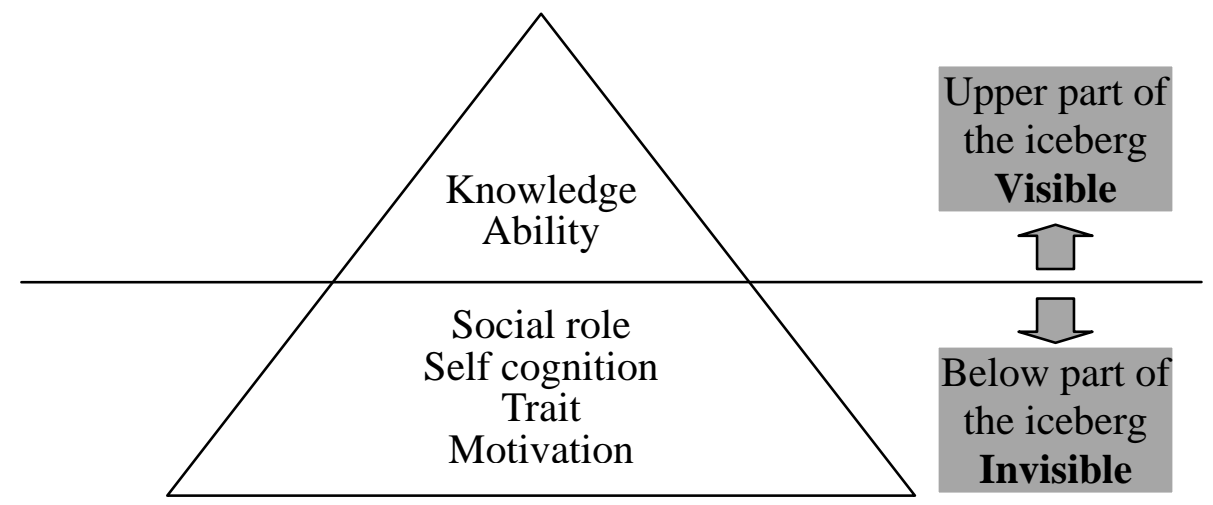

Fig. 2. Iceberg model

The constituent elements of the iceberg model shown in Fig.2 are briefly described as follows: knowledge refers to factual and experiential information that an individual has in a particular area; skill refers to the ability to use knowledge to accomplish a specific task structurally. That is, the mastery of the required technology and knowledge in a particular field; social roles, the behavioral styles and styles of a person based on attitudes and values; self-recognition, the attitudes, values, and self-images of a person; traits, personality, the continuous response of physical characteristics to the environment and all kinds of information. Quality and motivation can predict the state of the individual's work under long-term unsupervised conditions. Motivation refers to the natural and continuous thoughts and preferences in a particular field that will drive, guide, and determine a person's external actions.

\section{Construction Method of Competency Model}

In the process of constructing the professional competency model, it is necessary to grasp the competency characteristics of occupations, focusing on the selection of situational judgment test methods, including events, interviews, job analysis, and questionnaire surveys. The behavioral event interviewing method is an open behavioral retrospective exploration technique and is the main tool for revealing the competency characteristics. The main process is to ask interviewees to recall key examples of the most sense of achievement (or frustration) in the past six months (or one year), including the situation description, who participated, what actions were taken, and what the individual had and how are the feelings and results?

This method is currently most commonly used in the process of building the competency model. Interviewees are the objects of the target job. Through in-depth interviews with interviewees, successful and unsuccessful event descriptions during interviews are collected and the impact is explored. The detailed behavior of the target job capabilities. Then, collect, analyze, and code the specific events and behaviors that have been collected. Finally, the comparison is made between 
different interviewed groups to find the core competencies of the target positions. The interview steps are shown in Fig.3.

The behavioral event interview method has very high requirements for interviewers. Only professionally trained interviewers can continuously obtain effective interviews and obtain specific events related to the target job. In the actual application process, more simplified models are used and combined with other methods. The simplified model mainly retains information collection methods for behavioral event interviews and is used to determine the operational definition and behavior description of the capability model. Whether it is a complex behavioral event interview or a simplified behavioral event interview, the results can be directly applied to talent selection, assessment or training.

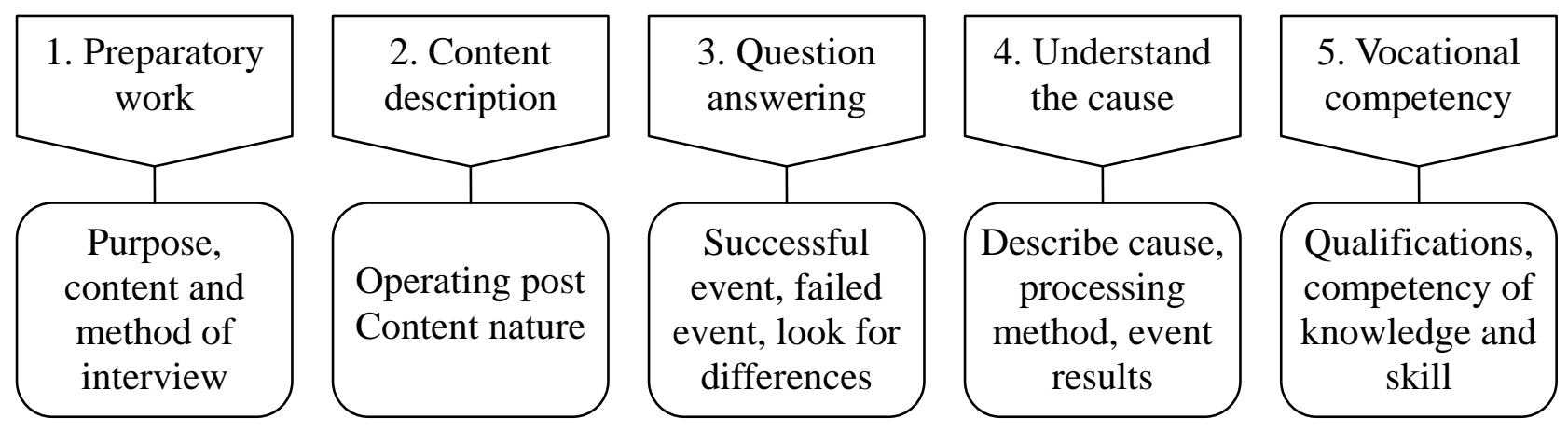

Fig. 3. The steps of the behavioral event interview

\section{Construction on Vocational Competency Model}

In the era of intelligent tourism, the rich tourism experience possessed by excellent tourism practitioners will be quickly acquired from the data center through mobile devices. Intelligent tourism has realized the interaction of the government, tourism companies, and tourists from time to time. Problems will also be quickly reflected in tourism companies and relevant government departments. Through the rapid response and coordination of various departments, relevant professionals will be mobilized to solve problems quickly. The role of personnel is weakened. This is not only a profound reform of the tourism industry, but also a new challenge to the training of tourism professionals. In the era of intelligent tourism, it is necessary to have tourism talents with the following characteristics: first, tourism talents with interdisciplinary knowledge background. Intelligent tourism is the product of the integration of the tourism industry and the information industry. Intelligent tourism talents must not only possess the basic theory of tourism, but also master professional knowledge. Second, tourism professionals who provide personalized service capabilities. Intelligent tourism is based on tourists and meets the individual needs of tourists. It classifies the individual needs of tourists and enhances the tourist experience of tourists. Third, the use of digital talents with new media equipment capabilities. The development of tourism with new media equipment not only caters to the individual needs of tourists, but also expands the scale of the tourist source market for tourism. The use of digital new media equipment is one of the necessary capabilities of tourism talents. Fourth, the quality of intellectual service ourism talents. Requires the intelligent service concept for tourism practitioners, demonstrates the wisdom of the service, and becomes the thinking and intelligent talent.

In response to the demand for the professional ability of tourism professionals in the era of intelligent tourism, based on the iceberg model, participating in relevant documents, and using behavioral event interviews, this paper constructs a professional competence model for tourism talents in the era of Intelligent tourism, consisting of knowledge, capabilities, ideas, and traits. four-dimensional composition, as shown in Fig.4.

The relevant competency elements for each dimension shown in Fig.4 are briefly described as follows: 
(1) Knowledge dimension: Tourism basic knowledge, including background knowledge of tourism industry such as history, geography, ethnicity and religion, as well as tourism business knowledge; Laws and regulations knowledge, knowledge of current state policies, laws and regulations, and tourism industry rules and regulations; Information technology knowledge, information search capabilities and computer network technology, office automation and other basic knowledge; Social science knowledge, elaborate knowledge of various social phenomena and their development laws, foreign language service is particularly important for foreign language knowledge.

(2) Ability dimension: Interpersonal ability, properly handle internal and external relations with tourists, supervisors, and colleagues, and continuously improve the realm of interaction; Information service ability, providing hotels, restaurants, transportation, catering, entertainment, travel shopping, and social service information; Use of intelligent equipment, general-purpose intelligent devices such as mobile phones and tablets, some high-tech artifacts used in intelligent travel; Development and innovation ability, new ideas and new methods to serve tourists, and the opportunity and ability to handle problems at work.

(3) Ideological dimension: Vocational ethics, in line with the professional ethics, moral values, moral sentiments, and moral qualities; Professional dedication, adjusting personal behaviors to meet the requirements and interests of tourism business organizations, and loving their jobs; Sense of responsibility; In the work, the sense of responsibility to the customer, the company, the society, self, and others is courageous; Organizational discipline complies with the organizational principles, systems, resolutions, and other disciplines of the tourism industry, and obeys the leadership.

(4) Trait dimension: Service consciousness, the mental state and consciousness of working for customers, organizations, and others, trying to help and serve customers; Self management, the ability to continuously manage, control, and motivate oneself in order to achieve the objectives of the work; Physical and mental quality is a combination of physical and psychological qualities, and is the basis for engaging in social work; Occupational sensitivity, the responsiveness of tourist events, news, and digital travel work related things or events.
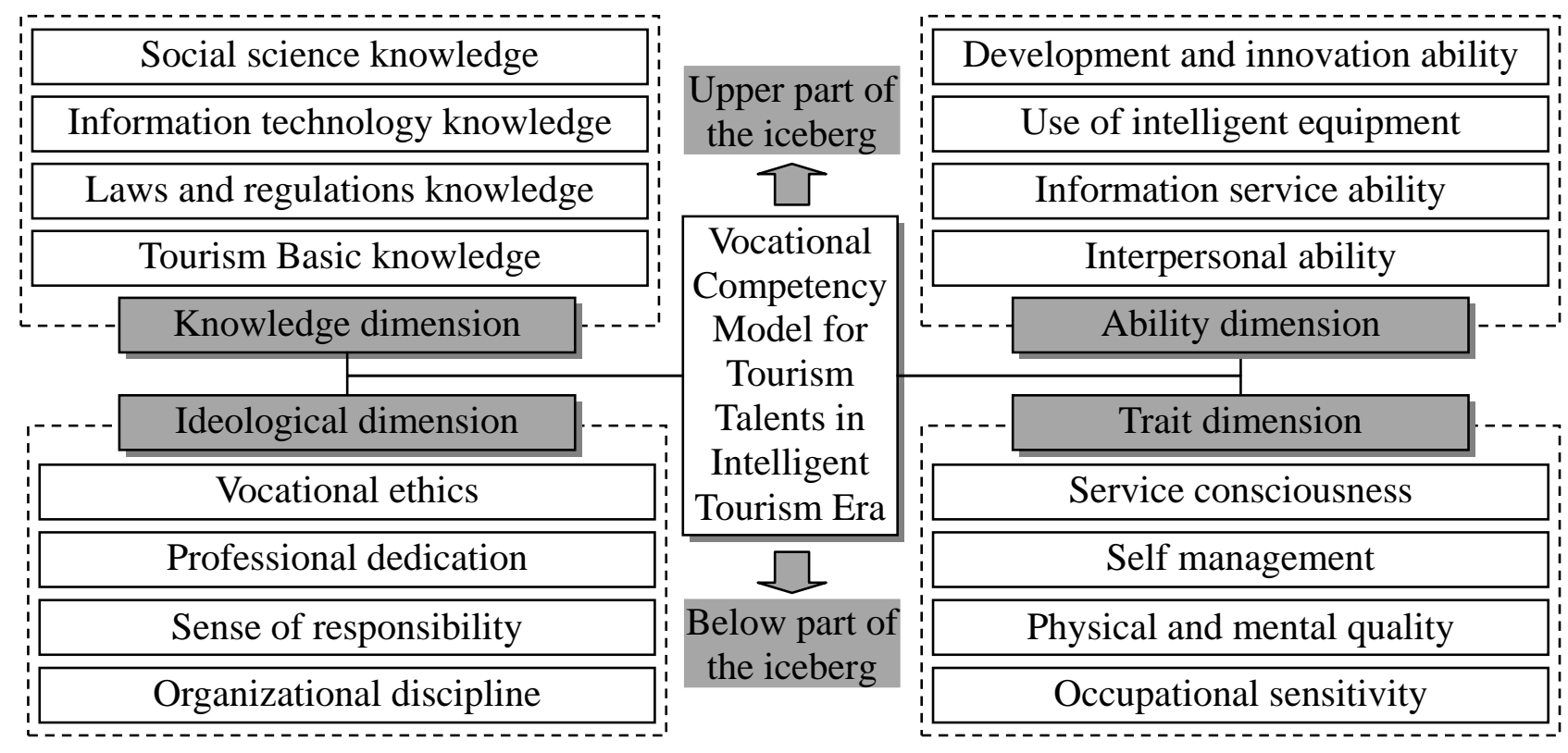

Fig. 4. Vocational competency model for tourism talents in intelligent tourism era

\section{References}

[1] Ulrike Gretzel, "Intelligent systems in tourism: A Social Science Perspective," Annals of Tourism Research, vol. 38, no. 3, pp. 757-779, 2011.

[2] Joan Borràs, Antonio Moreno, Aida Valls, "Intelligent tourism recommender systems: A survey," Expert Systems with Applications, vol. 41, no. 16, pp. 7370-7389, 2014. 
[3] X. Chen, "Analysis on the professional ability of foreign tour guides based on the development of Intelligent Tourism in Jiangsu," Journal of Hubei University of Economics (Humanities and Social Sciences), vol. 14, no. 8, pp. 25-26, 2017.

[4] H. T. Zhao, "A Survey on Competence Theory and its Application," Science and Management, vol. 29, no. 4, pp. 15-18, 2009.

[5] Y. L. Tang, L. Wang, Z. G. Zhang, "Exploration on the training mode of Intelligent Tourism Talents," Journal of Changchun Normal University, vol. 35, no. 9, pp. 51-52, 2015.

[6] J. Y. ZHang, "Suggestions and implementation of tourism talents training in Higher Vocational Colleges under the background of smart Tourism," Science \& Technology Industry Parks, vol. 18, no. 10, pp. 35-36, 2018. 